\title{
African trypanosomes
}

4 Authors: Guegan F. ${ }^{1 *}$, Bento F. ${ }^{1,2}$, Neves D. ${ }^{1}$, Sequeira M. ${ }^{1}$, Notredame C. ${ }^{3,4}$, and

5 Figueiredo L.M. ${ }^{*}$

$6 *$ Correspondence should be addressed to gueganfabien@gmail.com and

71 mf@medicina.ulisboa.pt

8 1. Instituto de Medicina Molecular - Joao Lobo Antunes, Faculdade de Medicina,

9 Universidade de Lisboa, Portugal

10 2. Current address: Institute of Molecular Biology and Institute of Developmental Biology

11 and Neurobiology, Johannes Gutenberg Universität, 55128 Mainz, Germany

12 3. Centre for Genomic Regulation (CRG), The Barcelona Institute of Science and

13 Technology, Dr. Aiguader 88, Barcelona 08003, Spain

14 4. Universitat Pompeu Fabra (UPF), Barcelona, Spain

Trypanosoma brucei causes African sleeping sickness, a fatal human disease. Its differentiation from replicative slender form into quiescent stumpy form promotes host survival and parasite transmission. Long noncoding RNAs (lncRNAs) are known to regulate cell differentiation. To determine whether lncRNAs are involved in parasite differentiation we used RNAseq to survey the $T$. brucei lncRNA gene repertoire, identifying 1,428 previously uncharacterized lncRNA genes. We analysed grumpy, a lncRNA located immediately upstream of an RNA-binding protein that is a key differentiation regulator. Grumpy over-expression resulted in premature

24 parasite differentiation into the quiescent stumpy form, and subsequent impairment of in vivo 25 infection, decreasing parasite load in the mammalian host, and increasing host survival. Our 
analyses suggest Grumpy is one of many lncRNA that modulate parasite-host interactions, and lncRNA roles in cell differentiation are probably commonplace in T. brucei.

\section{Keywords:}

Trypanosoma brucei, sleeping sickness, parasite, long non-coding RNAs, differentiation, stumpy forms.

\section{Introduction}

When T. brucei, a unicellular kinetoplastid parasite, reaches a critical density in the mammalian blood, a quorum-sensing mechanism is activated and the parasites differentiate into quiescent, non-dividing stumpy forms (Vassella et al., 1997), limiting parasite population size and extending host survival. The stumpy form also facilitates transmission to the tsetse fly vector and development into insect procyclic forms (Silvester et al., 2017). In T. brucei, parasite density is sensed via the stumpy induction factor (SIF) (Vassella et al., 1997) and the

SIF signaling pathway, which promotes gene expression, morphological, and metabolic changes associated with the stumpy form (Mony et al., 2014). To date, 43 genes have been identified to function in the SIF signaling pathway, ranging from signal transduction to signal response (Mony et al., 2014). RBP7 RNA-binding proteins (RBP7A and RBP7B) are effectors molecules of this pathway controlling downstream gene expression. RBP7A/B null mutant parasite become unresponsive to SIF signal and are unable to differentiate into stumpy forms. RBP7 genes are therefore key regulators of parasite differentiation, yet their mode of action and target genes are unknown (McDonald et al., 2018; Mony and Matthews, 2015). (Rinn and Chang, 2012). LncRNAs function in many cellular pathways (Carlevaro-Fita and Johnson, 2019; Geisler and Coller, 2013; Yao et al., 2019), including cell differentiation (Flynn and Chang, 2014; Ransohoff et al., 2018). LncRNAs can regulate cell fate choice by either 
promoting or inhibiting differentiation. In skin stem cells, ANCR (anti-differentiation noncoding RNA) and TINCR (terminal differentiation noncoding RNA) lncRNAs function antagonistically. While ANCR suppresses epidermal differentiation pathway and maintains the stem cell compartment, TINCR promotes epidermal terminal differentiation (Kretz et al., 2013, 2012). LncRNAs are also important players in parasite infections, regulating antigenic variation of Plasmodium falciparum (Amit-Avraham et al., 2015; Guizetti et al., 2016) and associated to the host cell response in Toxoplasma gondii infection (Menard et al., 2018).

To date, only 95 putative lncRNA genes have been annotated in T. brucei, all with unknown functions (Kolev et al., 2010). This small number, compared to 9598 T. brucei protein coding genes (Aslett et al., 2009), prompted us to analyze the non-coding repertoire of T. brucei and to determine if lncRNAs are regulators of parasite differentiation.

\section{Results and Discussion}

We used a combination of strand-specific and paired-end RNASeq, in-silico analysis, and database integration to re-annotate the lncRNA gene repertoire of T. brucei (Figure 1A figure supplement 1-5). We identified 1,428 previously uncharacterized transcripts longer than $200 \mathrm{nt}$, having no significant coding potential, few ribosomal interactions, and which do not encode any unique peptides (table supplement 1 and 2 - figure supplement 2-5). These putative IncRNAs are scattered throughout the 11 chromosomes of the T. brucei genome in a mostly intergenic fashion (figure supplement 6). They are shorter, less expressed, and less GC-rich than T. brucei protein coding mRNAs (figure supplement 7) but they otherwise harbor regular mRNA trans-splicing/polyadenylation motifs (figure supplement 8). We detected these transcripts either in the nucleus and/or the cytoplasm of various T. brucei life cycle stages (Figure 1B). In total, 25\% of the lncRNA transcripts are differentially expressed between mammalian bloodstream and insect procyclic forms (figure supplement 9 - table supplement 
3), compared to $16 \%$ of differentially expressed proteins coding transcripts. LncRNA gene repertoire in T. brucei is substantial (11\% of total genes) and shows a high dynamic expression pattern during the parasite life cycle.

We analyzed an RNAi screen data output (Alsford et al., 2011) to test our hypothesis that lncRNAs are involved in parasite differentiation. We found a total of 399 lncRNA genes that appear to be required for differentiation to occur (Figure 1C - table supplement 4), consistent with our expectation that $T$. brucei lncRNA regulate parasite transition and adaptation between mammalian and insect vector hosts. LncRNAs have been reported to regulate cell differentiation by modulating expression of their neighboring genes (Flynn and Chang, 2014). We found 19 T. brucei lncRNAs genes located immediately upstream or downstream of 18 of the 43 SIF pathway genes (table supplement 5). The lncRNA Ksplice3137a, which we named grumpy (for regulator of Growth and Stumpy formation), is located upstream of RBP7A and RBP7B, which are both required for SIF-induced stumpy formation (Mony et al., 2014). grumpy's pattern of expression is similar to that of RBP7, which is transcribed both in the bloodstream and procyclic forms of T. brucei (Figure 2A). However, unlike RBP7 transcripts, grumpy does not interact with T. brucei ribosomes (Figure 2A) and does not produce detectable peptides (table supplement 2).

To further characterize the grumpy transcript, we used a circular RT-PCR (cRT-PCR) assay, in which T. brucei RNAs are circularized via their 5' - 3' end junctions, amplified and sequenced. We used gene-specific primers to confirm that grumpy is a trans-spliced and polyadenylated lncRNA transcript expressed as at least five different isoforms, including the 100 smallest (359bp), the major (397 bp) and longest forms (432 bp) (Figure 2B). These findings are consistent with the Ksplice in-silico analysis, which revealed one splice-acceptor site and 10 alternative polyadenylation sites for grumpy (Figure 2B). RT-qPCR showed that, while the mRNA levels of RB7B decrease during parasite differentiation from slender to stumpy forms, 
grumpy levels remain constant (Figure 2C). However, an RNA-FISH analysis revealed changes slender forms grumpy localizes in three distinct nuclear foci (one in the nucleolus and two in the nucleoplasm), in stumpy forms grumpy localizes in a single nucleolar focus (Figure 2D). Contrary to our initial hypothesis, these changes in subcellular localization suggest that grumpy may act through a trans-acting mechanism.

To identify the function of grumpy, we used a gain-of-function approach, in which

111 grumpy was over-expressed 3-fold from an exogenous genomic location (mini-chromosome).

112 These exogenous grumpy transcripts retained the original nucleolar localization and the

113 transcript levels of RBP7A and B remained unchanged (Figure 3A and B). We observed that

114 exogenous expression of grumpy repressed T. brucei growth and increased lifespan in vitro

115 (Figure 3C and D). We asked whether this reduction in parasite growth could be explained by

116 a higher proportion of the stumpy forms in culture. Stumpy formation occurs only at high

117 parasite density via the SIF-dependent quorum-sensing mechanism, and can be quantified

118 using flow cytometry (Batram et al., 2014; Dean et al., 2009) by measuring the fraction of

119 transgenic parasite expressing the fluorescent stumpy marker GFP::PAD1. After 2 days in culture, $60 \%$ of the grumpy over-expressing parasites with were in the stumpy form, compared to $7 \%$ in the parental line cultured for the same time period (Figure 3E). Grumpy overexpression also lead to a lower parasite density $\left(<0.7 \times 10^{6}\right.$ cells $\left./ \mathrm{ml}\right)$ compared to the parental culture $\left(1.4 \times 10^{6}\right.$ cells $\left./ \mathrm{ml}\right)$ (Figure 3C). Parasites over-expressing grumpy displayed all

124 hallmarks of being in stumpy form, including PAD1 protein expression at the cell surface

125 (Figure 3F), arrest at the cell cycle G0/G1 phase (Figure 3G), and pre-adaptation to differentiate into the insect procyclic stage (Figure $3 \mathrm{H})$.

To confirm these results in-vivo, we induced mouse infections with parasites over- 
were compared to infection by the parasite parental line. Mice infected with the parental cell

130 line showed a typical infection profile characterized by successive waves of parasitemia

131 (Figure 4A) and an average survival of 43 days (Figure 4B) (Trindade et al., 2016). By contrast,

132 mice infected with parasites over-expressing grumpy showed no detectable parasitemia and did

133 not die from the infection (>100days) (Figure 4A and B). When grumpy over-expression was

134 induced four days post-infection, the parasites succeeded in establishing an infection (Figure

135 4A), with three mice out of four dying from the infection and mice survival time increasing

136 from approximately 43 to 72 days (Figure 4B). Thus, grumpy over-expression substantially

137 reduces parasite virulence in mice.

Our in vivo analysis also recapitulated in vitro observations with respect to stumpy

139 forms and density. Wild-type parasites started differentiating into stumpy forms ( $>20 \%$ stumpy

140 forms in the blood) only at high parasitemia $\left(>1.5 \times 10^{7}\right.$ parasites $\left./ \mathrm{ml}\right)$ whereas grumpy-over-

141 expressing parasites differentiated into stumpy forms when parasitemia was as low as $1.1 \times 10^{6}$

142 parasites/ml (Figure 4C). These results support the notion that grumpy over-expression triggers

143 premature $T$. brucei differentiation into stumpy forms, which is associated with a reduction in

144 parasite virulence.

Here, we show that the grumpy lncRNA is a regulator of parasite differentiation in $T$.

brucei. Its mechanism of action, currently unknown, does not correlate to RBP7 expression but

147 likely involves its nucleolar localization. This localization is seen for the mammal $\mathrm{X}$

148 inactivation factor, Xist, and pRNA, a promoter-associated RNA that drives mouse embryonic

149 stem cell differentiation (Savić et al., 2014; Zhang et al., 2007). Both of these lncRNAs

150 promote heterochromatin formation at the nucleolar periphery. Other lncRNAs bind and

151 sequestrate specific proteins in the nucleolus, rendering them functionally inert (Audas et al.,

152 2012). Grumpy could regulate stumpy formation through similar mechanisms either by

153 sequestering stumpy regulator proteins (or its mRNAs) or by modulating the genomic 
conformation of stumpy regulator genes within the nucleolus. In the future, it will also be important to evaluate if grumpy is necessary for stumpy formation. This will require careful genome editing given that part of the grumpy lncRNA shares sequence homology with RBP7A

157 3'UTR.

158

Materials and Methods

\section{$\underline{T . \text { brucei cell culture }}$}

177 A stumpy reporter cell line with a GFP:PAD1UTR construct (Batram et al., 2014) integrated

Of the 1,428 lncRNA genes we have identified in T. brucei, 649 have been predicted, via an RNAi screen, to play a role in parasite fitness, including 399 lncRNA genes involved in cell differentiation (Figure 1C). That 18 of the 41 genes involved in the quorum-sensing signaling pathway have a lncRNA gene in close proximity suggests that grumpy's role in differentiation may be only one instance of a more general process used by the parasite to sense its environment and modulate its virulence accordingly. Understanding these regulatory processes may open up possibilities for developing therapeutic strategies to treat sleepiness sickness.

\section{$\underline{\text { Ethics statement }}$}

Male C57BL/6J (6-8 weeks old) were purchased from Charles River Laboratories (Lyon, France). All animal care and experimental procedures were performed according to EU regulations (Directive 2010/63/EU9) and approved by the Animal Ethics Committee of Instituto de Medicina Molecular João Lobo Antunes (AWB2016_19FG_RNA). into the tubulin locus was generated in T. brucei Antat1.1e (90:13) strain (Engstler and Boshart, 
2004). The stumpy reporter cell line was selected for its most intense GFP expression, which occurs in the nucleus in response to quorum-sensing signal. This reporter cell line was used as

181 the genetic background to overexpress for Grumpy-lncRNA. It was cultivated in HMI-11 at $18237^{\circ} \mathrm{C}$ in $5 \% \mathrm{CO}_{2}$ with $2,5 \mu \mathrm{g} / \mathrm{mL}$ G418, $5 \mu \mathrm{g} / \mathrm{mL}$ Hygromycin $\mathrm{B}, 5 \mu \mathrm{g} / \mathrm{mL}$ Blasticidin $\mathrm{S}$ and $1832,5 \mu \mathrm{g} / \mathrm{mL}$ Phleomycin.

\section{Grumpy-IncRNA expression construct}

186 The non-coding sequence of Grumpy lncRNA was amplified from T. brucei Antat 1.1E 187 genomic DNA with forward (5'-CAAAAGGACAGAATTATAGGTTCA-3') and reverse (5'188 GATGCAGCTCAACAGCAAG-3') primers and inserted into pDEX577 (phleo) between the 189 Hind III and BamH I sites of the plasmid. pDEX577 vectors are highly-modular expression vectors for inducible expression of transgenes, integrating in the minichromosome repeats, which was designed and constructed by Steve Kelly (Kelly et al., 2007). Moreover, two T7 terminator sequences were inserted between the BamH I and Kpn I sites of the plasmid just downstream to the Grumpy lncRNA construct. The construct was linearized with Not I prior to transfection. Stable transfectant clones were obtained by serial dilution of the transfected population and selected after 6-7 days after transfections. Inducible expression is obtained by adding Tetracycline (in vitro) or Doxycycline (in vivo) at the following concentrations: 1 $\mu \mathrm{g} / \mathrm{mL}$ and $1 \mathrm{mg} / \mathrm{ml}$.

199 Inducible expression of Grumpy-IncRNA

200 Cells were diluted at $5 \times 10^{4}$ parasites $/ \mathrm{mL}$ and induced with $1 \mu \mathrm{g} / \mathrm{mL}$ of tetracycline for 6 days.

201 Cells were counted every day, live/dead cells were assessed by Propidium iodide staining, 202 GFP::PAD1 positive cells were scored and all these parameters quantified using Accuri C6 203 flow cytometry. At day 2 after tetracycline induction, RNA samples were collected by 
centrifugation of equivalent number of cells and addition of TRIzol reagent (Invitrogen) to the

Propidium iodide staining in fixed cells.

208

\section{Quantitative RT-PCR}

210 RNA was prepared with TRIzol reagent (Invitrogen) according to manufacturer's instructions

211 and cDNA was synthesized with random primers and SuperScript II reverse transcriptase.

212 Quantitative PCR was performed with AmpliTaq Gold ${ }^{\mathrm{TM}}$ DNA Polymerase (Power SYBR

213 Green Master Mix, Applied Biosystems ${ }^{\mathrm{TM}}$ ) and gene-specific primers:

214 Control of Differentiation (Tb927.10.12970)

215 FW: CCAGCCTTCTCAATCTCCAG

216 Rv: GGCCACAGTTGGATAGCTTG

$217 \quad$ Tb927.10.12080

218 FW: CCTGCAGGCGTCACATTC

219 RV: CAGTGAAGAAGAAAAGGCACG

220 Grumpy lncRNA:

FW: AACGGAAGGAAAGTTTGTGAATGC

223 RBP7A:

224 FW: GCTCGACTTTTTGTTGGGCAG

RV: CATATTGTAGCGGTTGTGAAGCG

RBP7B: 
The quantitative PCR program was:

231 Stage $2-15 \mathrm{sec}$ at $95^{\circ} \mathrm{C}, 15 \mathrm{sec}$ at $60^{\circ} \mathrm{C}, 30 \mathrm{sec}$ at $72^{\circ} \mathrm{C}$ (40 cycles)

232 Melt curve $-15 \mathrm{sec}$ at $95^{\circ} \mathrm{C}, 1 \mathrm{~min} 10 \mathrm{sec}$ at $60^{\circ} \mathrm{C}, 15 \mathrm{sec}$ at $95^{\circ} \mathrm{C}$

\section{Stumpy formation assay}

235 Cell cultures were started at $5 \times 10^{4}$ parasite $/ \mathrm{mL}$ and induced or not with $1 \mu \mathrm{g} / \mathrm{mL}$ of tetracycline.

236 Every day of culture, sufficient number of cells (>10 000 parasites) were collected, washed 237 with trypanosome dilution buffer (TDB) $(5 \mathrm{mM} \mathrm{KCl}, 80 \mathrm{mM} \mathrm{NaCl}, 1 \mathrm{mM} \mathrm{MgSO} 4,20 \mathrm{mM}$ 238 Na2HPO4, $2 \mathrm{mM}$ NaH2PO4, $20 \mathrm{mM}$ glucose, $\mathrm{pH}$ 7.4), and resuspended in $200 \mu \mathrm{L}$ of TDB with $1 \mu \mathrm{g} / \mathrm{mL}$ Propidium iodide. A fixed volume of each cell culture was analysed by flow cytometry (Accuri C6) to simultaneously measure the parasites density, live and dead parasites and the GFP::PAD1 expression.

\section{Cell cycle profile assay}

244 Cell cultures were started at $5 \times 10^{4}$ parasite $/ \mathrm{mL}$ and induced or not with $1 \mu \mathrm{g} / \mathrm{mL}$ of tetracycline.

245 After 3 and 4 days of in vitro culture, $2 \times 10^{6}$ parasites were collected and span down (10 min, $1300 \mathrm{~g}, 4^{\circ} \mathrm{C}$ ), washed once with ice-cold PBS, resuspended in $1 \mathrm{ml} \mathrm{PBS} / 2 \mathrm{mM}$ EDTA and fixed by adding drop wise $2.5 \mathrm{ml}$ ice cold $100 \%$ ethanol (store $\mathrm{EtOH}$ at $-20^{\circ} \mathrm{C}$ ). Cells were fixed at $4^{\circ} \mathrm{C}$ for at least one hour, washed once with $1 \mathrm{ml}$ PBS/EDTA at RT and resuspended in $1 \mathrm{ml}$ PBS/EDTA. RNA was digested by adding $1 \mu 1 \mathrm{RNaseA}(10 \mu \mathrm{g} / \mu \mathrm{l})$ and DNA stained by adding $1 \mu \mathrm{l}$ propidiumiodide $(1 \mathrm{mg} / \mu \mathrm{l})$ during $30 \mathrm{~min}$ at $37^{\circ} \mathrm{C}$. Cell-cycle profile were analysed by

251 flow cytometry using Accuri C6 machine with FL3 channel.

\section{Parasite differentiation into procyclic assay}


254 Cell cultures of bloodstream forms were started at $5 \times 10^{4}$ parasite/mL and Grumpy lncRNA

255 was induced or not with $1 \mu \mathrm{g} / \mathrm{mL}$ of tetracycline. After 2 days of in vitro culture, the number

256 of stumpy forms were assessed by measuring the GFP::PAD1 expression using flow cytometry

257 (Accuri C6). Bloodstream forms culture were collected, span down, resuspended in

258 Differentiation Trypanosome Medium (DTM) with $6 \mathrm{mM}$ cis-Aconitate at $1 \times 10^{6}$ parasites $/ \mathrm{mL}$

259 and incubated at $27^{\circ} \mathrm{C}$. Parasite differentiation into procyclic forms was assessed at $12 \mathrm{~h}$ post

260 differentiation by Flow cytometry using anti- Trypanosoma brucei procyclin antibody (Clone

261 TBRP1/247, CLP001AP, 0.5mg, Cedarlane) conjugated with Alexa Fluor 647 (Protein

262 labelling kit, Molecular probes) (1/500 dilution in TDB).

\section{Infections and Sample Collection}

265 Four weeks old male c57BL/6 mice (Charles River, France) were inoculated intraperitoneally

266 with 2000 parasites. Mice were infected with either Antat1.1 90:13 GFP::PAD1 cell line or

267 Antat1.1 90:13 GFP::PAD1 Grumpy-overexpression cell line. Mice infected with Antat1.1

268 90:13 GFP::PAD1 Grumpy-overexpression parasites were separated in three different cages,

269 one cage of 4 mice received only water, one cage of 4 mice received water with $1 \mathrm{mg} / \mathrm{ml}$

270 doxycycline hyclate (Sigma-Aldrich) at day 4 post infection, one cage of 3 mice received water

271 with $1 \mathrm{mg} / \mathrm{ml}$ doxycycline hyclate at the day of infection. Parasitaemia was monitored by tail-

272 vein bleeds every other day and counted using a Hemocytometer with 1:150 blood dilution in

273 TDB. The percentage of stumpy forms in the mice blood were assessed by measuring

274 GFP::PAD1 expression in blood diluted sample using Accuri C6 flow cytometer. Mice survival

275 were monitored every other day until 100 days post infections. Mice were euthanized at the

276 first signs of severe disease distress, with all efforts to minimize animal suffering. 
Between $2,5 \times 10^{5}$ to $1 \times 10^{6}$ cells were harvested by centrifugation (10 min, $\left.1800 \mathrm{~g}\right)$, washed

RNAse-free PBS. Cells were then settled on pre-coated polylysine culture dishes (35mm glass bottom, MatTEK) for at least 20 min. PBS was removed and cells were permeabilized with 1

Buffer A, Biosearch Technologies Cat\# SMF-WA1-60). Cells were incubated with $100 \mu \mathrm{L}$ Hybridization buffer containing $1,25 \mu \mathrm{M}$ of RNA-FISH probes in the dark at $37^{\circ} \mathrm{C}$ overnight ( $\sim 16$ hours). Cells were washed with $200 \mu \mathrm{L}$ of wash buffer A and incubated $200 \mu \mathrm{L}$ of wash buffer $\mathrm{A}$ in the dark at $37^{\circ} \mathrm{C}$ for 30 minutes. Cells were stained with a solution of $1 \mu \mathrm{g} / \mathrm{mL}$ of DAPI (in wash buffer A) in the dark at $37{ }^{\circ} \mathrm{C}$ for 30 minutes. Cells were washed with $200 \mu \mathrm{L}$ of wash buffer B (Biosearch Technologies Cat\# SMF-WB1-20) and incubated with it at room temperature for 2-5 minutes. $100 \mu \mathrm{L}$ Vectashield was added to the dishes prior analysis with the Zeiss cell observer wild Field microscope.

RNA-FISH probes were designed using the online tools provide by LGC Biosearch Technologies (Stellaris Probe Designer, https://www.biosearchtech.com/support/tools/designsoftware/stellaris-probe-designer). 17 probes were designed for Grumpy lncRNA, and 30-43 probes for Ksplice lncRNA223a, lncRNA1077a, lncRNA1735a and lncRNA5090a.

\section{PAD1 staining}

$3015 \times 10^{5}$ bloodstream form parasites were harvested by centrifugation (10 min, $\left.1800 \mathrm{~g}\right)$, washed with $1 \mathrm{X}$ PBS and resuspended in $500 \mu \mathrm{L}$ of fixation buffer (4\% paraformaldehyde diluted in 1X PBS) for $10 \mathrm{~min}$ at room temperature. Fixed cells were washed with $500 \mu \mathrm{L} 1 \mathrm{X}$ PBS and 
resuspended with $100 \mu \mathrm{L}$ of $1 \mathrm{X}$ PBS. Cells were then settled on pre-coated polylysine culture permeabilized with $100 \mu \mathrm{L}$ of $0,1 \%$ Triton in PBS for 2 min at room temperature. for $45 \mathrm{~min}$ at $37^{\circ} \mathrm{C}$ in a humidity chamber. Cells were incubated with $100 \mu \mathrm{L}$ of the primary antibody anti-PAD1 (1/1000 in 2\% BSA in PBS, antibody provided by Keith Matthews) overnight at $4{ }^{\circ} \mathrm{C}$ in a humidity chamber. Cells are washed 5 times with $200 \mu \mathrm{L}$ of PBS and

311 incubated with $100 \mu \mathrm{L}$ of the secondary antibody anti-rabbit (1/1000 in $2 \%$ BSA in PBS, Goat

312 anti-Rabbit Alexa Fluor 647 \#A21245 - Invitrogen) for 45 min at $4{ }^{\circ} \mathrm{C}$ in a humidity chamber.

313 Parasite DNA was stained using $100 \mu \mathrm{L}$ DAPI or Hoechst solution $(1 \mu \mathrm{g} / \mathrm{ml})$ for $20 \mathrm{~min}$ at

314 room temperature. Cells were washed 5 times with $200 \mu \mathrm{L}$ of PBS and $100 \mu \mathrm{L}$ Vectashield was added to the dishes prior analysis with the Zeiss cell observer wild Field microscope.

\section{Transcript quantification and Circular RT-PCR}

318 Transcript quantification was performed by quantitative RT-PCR, as described in Aresta-

319 Branco et al. (Aresta-Branco et al., 2015) except that random hexamer primers were used to 320 generate cDNA.

321 Circular RT-PCR protocol was performed essentially as described in Laboratory Methods in 322 Enzymology book (ABELSON and SIMON, 2009). Briefly, parasites were harvested by 323 centrifugation $677 \mathrm{~g}$ for $10 \mathrm{~min}$ at $4{ }^{\circ} \mathrm{C}$ and immediately resuspended in TRIzol (life 324 technologies). Total RNA is isolated following the manufacturer's instructions and RNA was quantified in a NanoDrop 2000 (Thermo Fisher Scientific). The ideal RNA concentration to perform the circular RT-PCR protocol is $0.5-1 \mathrm{mg} / \mu 1$. RNA cap and poly A tail were removed by oligonucleotide-directed RNase $\mathrm{H}$ cleavage using Spliced-leader and oligo dT primers.

328 After RNAse $\mathrm{H}$ treatment, RNA was extracted with phenol/chloroform approach and 
precipitated using ethanol precipitation protocol. 3-5 $\mu \mathrm{g}$ of RNAse $\mathrm{H}$ treated RNA was

331 extracted with phenol/chloroform approach and ethanol precipitated. RNA was reverse

332 transcribed using gene-specific primer R1 (100 nucleotides from the 5'end of the transcript or

333 the RNase $\mathrm{H}$ cleavage site) and reverse transcriptase, RT buffer and 5mM Magnesium from

334 Superscript II kit (life technologies). The resulting cDNA molecules contain the juxtaposed 5' and 3'ends of circular RNA. PCR is performed on the produced cDNA using gene-specific primers R2 and forward F1. R2 primer is in "nested" position compared to R1 primer and contributes to the specificity of PCR amplicon. PCR\#1 product was purified using Minielute PCR purification kit (Qiagen) and a second round of PCR amplification was performed with gene-specific primers R2 and forward F2. F2 primer is in nested position compared to F1 primer position and contributes to PCR amplicon specificity. PCR\#2 product was ligated to pGEM-T easy vector or TOPO vector following the manufacturer's instructions (Promega). After transformation in bacteria and plasmid amplification, the subcloned PCR\#2 fragments were amplified and sequenced using T7 and SP6 primers.

\section{RNA-Sequencing}

T. brucei bloodstream-form (BSF) and procyclic-form (PF) parasites (strain Lister 427, antigenic type MiTat 1.2, clone 221a), from PL1S cell line (Yang et al., 2009), were used to generate strand-specific libraries following the manufacture instructions (Encore ${ }^{\circledR}$ Complete RNA-Seq Library Systems, NuGen) for Illumina next-generation paired-end sequencing. 


\section{Reconstruction of $T$. brucei transcriptome}

355 In T. brucei, all mature mRNAs are trans-spliced and polyadenylated which means that all 356 mRNA transcripts start with a conserved spliced-leader sequence and finish with poly(A) tail 357 sequence ${ }^{31}$. We hypothesized that any new T. brucei transcripts including noncoding RNA 358 transcripts will bear these features. RNA-seq reads were assessed for quality using FastQC. In order to improve genome mappability, RNA-seq reads size were increased, if possible, by merging the paired-end reads using PEAR software - Paired-End reAd mergeR (https://cme.hminimum of $8 \mathrm{bp}$ matching the SL sequence on their $5^{\prime}$, end were extracted for $5^{\prime}$ spliceacceptor site detection and the SL sequenced removed from the read. Reads containing stretches of at least 9 A's in the merged reads, or 9 T's in the unmerged reverse reads were extracted for poly-A site identification and and the poly-A tails removed from the read. annotation: version v5.1) using LAST (version 959) alignment tools (Kielbasa et al., 2011) (http //last.cbrc.jp/). 5' splice-acceptor sites were determined by the first position of all SLcontaining reads mapping uniquely to the genome. Poly-A sites were determined by the last position of all uniquely mapped poly-a containing reads. SL acceptor or polyA sites were considered for further analysis if a splice-acceptor or polyA site is supported by at least 5 reads. Putative T. brucei genes were defined by all genomic regions separated by at least one 5, acceptor site and one 3' poly-A site occurring before the next downstream 5' site. For each gene region, the longest transcript isoform was defined by the association of the most upstream SL-acceptor site and the most downstream polyA site. In contrary, the major isoform of $T$. 


\section{Identification of Ksplice putative new noncoding genes}

381 A stringent selection pipeline was developed to systematically identify T. brucei non-coding

382 RNAs. This pipeline aims to discard housekeeping (tRNAs, snRNAs, snoRNAs) T. brucei non-

383 coding RNAs and transcripts with protein-coding potential. First, only transcripts that do not overlapped annotated protein-coding and non-coding RNA genes from Tritryp data (https://ritrypdb.org/tritrypdb/ ; genome annotation: version v5.1) were retained. Second, $T$. brucei transcripts with protein-coding potential were excluded. Protein-coding potential was determined by using three different approaches. 1) The protein-coding potential for each transcript was calculated using coding potential calculator score (CPC2) (Kang et al., 2017).

2) The association with $T$. brucei ribosomes and translation efficacy of each transcript was measured using the published ribosome profiling data from T. brucei (Vasquez et al., 2014) and re-analysing it with our Ksplice gene annotation. 3) The non-coding potential of each transcript were confirmed using Proteomics data from three different lifecycle stage of $T$. brucei (Dejung et al., 2016). Each transcript with non-coding potential defined in part 1) and 2) and not encoding any peptides or encoding solely non-unique peptides in part 3) were classified a Ksplice noncoding RNA genes.

398 The longest isoform of each Ksplice genes were used for CPC2 analysis. CPC2 (Kang et al., 399 2017) discriminates coding and non-coding DNA sequences based on four intrinsic features: 400 Fickett TETSCODE socre, open reading frame (ORF) length, ORF integrity and isoelectric 401 point $(\mathrm{pI})$. The Fickett TESTCODE score was calculated from the weighted nucleotide 402 frequency of the full-length transcript whereas the ORF length, ORF integrity and pI were 403 calculated from the longest putative ORF identified in each gene. A CPC2 score below 0.5 
defined a transcript as non-coding gene, whereas a CPC2 score $\geq 0.5$ describes a transcript as protein-coding gene.

406

\section{7 (2) Ribosome profiling}

408 T. brucei ribosome profiling data (Vasquez et al., 2014) was re-analyzed using our merged 409 genome annotation that consisted of the annotated protein-coding genes from TriTrypDB and

410 our new annotated Ksplice noncoding genes (major isoforms). Quantification and statistical 411 analysis were performed as described in Vasquez et al. (Vasquez et al., 2014). A T. brucei 412 transcript was defined to be interacting productively with ribosomes if its translation efficacy 413 score was $\geq 1$ (translation efficacy $=\mathrm{TE}=\mathrm{RPKM}$ of ribosome profiling $/$ RPKM of RNA-seq).

414 Inversely, A T. brucei transcript was defined to be not interacting with ribosomes if its 415 translation efficacy score was $\leq 0.2857$, meaning its transcript levels (RNA-seq data in RPKM) 416 was 3.5x higher than its level of association with T. brucei ribosomes. And a T. brucei transcript 417 with TE score in between $(0.2857<\mathrm{TE}<1)$ was defined to have low or few interaction with 418 T. brucei ribosome. Additionally, as in Vazquez et al. (Vasquez et al., 2014), we investigated 419 the 5' end periodicity of mapped reads of both coding and putative non-coding genes. For 420 Figure supplement 6, for each gene, the number of reads mapping to each frame of translation 421 (represented as $+0,+1$ and +2 ) was calculated, and the frame with the highest number of mapped reads was determined. A p-value indicating the likelihood of periodicity was calculated by a binomial test on the frame with the highest number of mapped reads under the null-hypothesis that this number should be equal to $1 / 3$ of all reads mapped to that gene. 
427 The mass spectrometry proteomics data from Dejung et al. (Dejung et al., 2016) was analyzed

428 following the author's methodology with some modifications using MaxQuant version 1.6.0.1

429 (Cox and Mann, 2008) and searching against our Ksplice protein database. Our Ksplice protein

430 database is composed by 3 set of proteins - protein-coding genes from TryTrypDB (version

43133,10019 entries, excluding protein-coding genes with internal codon stop), putative proteins originated from the Ksplice new gene sequences (2003 Ksplice new genes +72 Ksplice Kolev ncRNAs) and putative proteins originated from intergenic region sequences of $T$. brucei genome. Intergenic region sequences were selected to have on average the same size and number of sequences than Ksplice new genes. All Putative protein sequences (enclosed by a start and stop codon, with a minimum of 7 amino acids and a maximum of $4600 \mathrm{Da}$ ) originating from Ksplice new genes or intergenic regions of T. brucei genome were extracted in order of the DNA sequence and from the 3 possible translation frames (excluding sequences without start codon or/and containing ambiguous base). 14261 proteins were extracted from Ksplice new genes and 28750 proteins from the selected intergenic region of $T$. brucei genome.

\section{$442 \quad$ Full length sequencing}

443 To investigate the presence of full length transcripts in our RNA-seq dataset, read pairs 444 containing the SL sequence on the forward read and a poly-A tail on the reverse read were 445 extracted and mapped to the T. brucei genome as described above (in identification of Ksplice 446 putative new noncoding genes section). For all concordant alignments (both paired reads 447 aligned), the boundaries of the transcripts were determined by the mapping positions of the two 448 reads. Paired-end reads are providing the accurate boundaries of $T$. brucei transcripts as reads 449 are sequenced from the same RNA molecule. 
452 Differential expression analysis for Ksplice new genes between bloodstream and procyclic

453 froms was performed using our merged annotation of T. brucei genome (major isoform of 454 Ksplice new genes + Tritryp protein-coding genes) and the DEseq2 package. To that end, we 455 used our previously published transcriptomic data (Rijo-Ferreira et al., 2017) containing 13 456 RNA-seq samples replicate for both bloodstream and procyclic forms.

\section{RIT-seq analysis of Ksplice new genes}

459 The RIT-seq data from Alsford et al. (Alsford et al., 2011) was re-analyzed by aligning the 460 sequence reads against our merged annotation of T. brucei genome (major isoform of Ksplice 461 new genes + Tritryp protein-coding genes). Quantification and statistical analysis were performed as described in Alsford et al. (Alsford et al., 2011).

\section{$\underline{\text { Statistical analysis }}$}

For all graphs in Figure $2 \mathrm{C}$ and Figure $3 \mathrm{C}-\mathrm{H}$ : the results are shown as mean (SEM, n=3) and all statistical analyses are done with two-factor mixed ANOVA (two-sided). For graph in

Figure 4A: the results are shown as mean (SEM, $n=4)$ and statistical analyses are done with two-way ANOVA (two-sided). For graphs in Figure 4B and 4C: the results are shown as mean (SEM, $\mathrm{n}=4)$ and statistical analyses are done with Log-rank (Mantel-Cox) test.

\section{Acknowledgment}

473 The authors would like to thank Marta Machado for her precious help with the in vivo mouse assistance in preparing the manuscript. 


\section{Authors' contributions}

479 FG, CN and LMF designed the study. FG, FB, DN, MS designed and performed the

experiments. FG, DN and LMF analyzed the data and wrote the initial draft of the manuscript.

FG and LMF supervised the project. All authors edited and approved the final manuscript.

482

483

\section{Competing interests}

The authors declare that they have no competing interests.

\section{Funding}

This work was supported in part by Fundação para a Ciência e Tecnologia (FCT)

Scientist Program [55007419]. LMF is supported by FCT (IF/01050/2014 and CEEC

institutional program). CN acknowledge the support of the Spanish Ministry of Economy,

Industry and Competitiveness (MEIC) to the EMBL partnership, the Centro de Excelencia

Severo Ochoa and the CERCA Programme / Generalitat de Catalunya.

492

493

494

495

496

497

498

499

500

501

502

503

\section{References}

ABELSON JN, SIMON MI. 2009. METHODS IN ENZYMOLOGY, Academic Press Inc., New York. doi:10.1016/S1554-4516(09)09011-5

Alsford S, Turner DJ, Obado SO, Sanchez-Flores A, Glover L, Berriman M, Hertz-Fowler C, Horn D. 2011. High-throughput phenotyping using parallel sequencing of RNA interference targets in the African trypanosome. Genome Res 21:915-924. doi:10.1101/gr.115089.110

Amit-Avraham I, Pozner G, Eshar S, Fastman Y, Kolevzon N, Yavin E, Dzikowski R. 2015. Antisense long noncoding RNAs regulate var gene activation in the malaria parasite Plasmodium falciparum. Proc Natl Acad Sci U S A 112:E982--E991. doi:10.1073/pnas.1420855112

Aresta-Branco F, Pimenta S, Figueiredo LM. 2015. A transcription-independent epigenetic mechanism is associated with antigenic switching in Trypanosoma brucei. Nucleic Acids Res 44:3131-3146. doi:10.1093/nar/gkv1459

Aslett M, Aurrecoechea C, Berriman M, Brestelli J, Brunk BP, Carrington M, Depledge DP, Fischer S, Gajria B, Gao X, Gardner MJ, Gingle A, Grant G, Harb OS, Heiges M, HertzFowler C, Houston R, Innamorato F, Iodice J, Kissinger JC, Kraemer E, Li W, Logan FJ, Miller JA, Mitra S, Myler PJ, Nayak V, Pennington C, Phan I, Pinney DF, Ramasamy G, Rogers MB, Roos DS, Ross C, Sivam D, Smith DF, Srinivasamoorthy G, 
Stoeckert CJ, Subramanian S, Thibodeau R, Tivey A, Treatman C, Velarde G, Wang H. 2009. TriTrypDB: A functional genomic resource for the Trypanosomatidae. Nucleic Acids Res 38:457-462. doi:10.1093/nar/gkp851

Audas TE, Jacob MD, Lee S. 2012. The nucleolar detention pathway: A cellular strategy for regulating molecular networks. Cell Cycle 11:2059-2062. doi:10.4161/cc.20140

Barquilla A, Crespo JL, Navarro M. 2008. Rapamycin inhibits trypanosome cell growth by preventing TOR complex 2 formation. Proc Natl Acad Sci 105:14579-14584. doi: $10.1073 /$ pnas.0802668105

Batram C, Jones NG, Janzen CJ, Markert SM, Engstler M. 2014. Expression site attenuation mechanistically links antigenic variation and development in Trypanosoma brucei. Elife 3:1-18. doi:10.7554/elife.02324

Carlevaro-Fita J, Johnson R. 2019. Global Positioning System: Understanding Long Noncoding RNAs through Subcellular Localization. Mol Cell 73:869-883. doi:10.1016/j.molcel.2019.02.008

Cox J, Mann M. 2008. MaxQuant enables high peptide identification rates, individualized p.p.b.-range mass accuracies and proteome-wide protein quantification. Nat Biotechnol 26:1367-1372. doi:10.1038/nbt.1511

Dean S, Marchetti R, Kirk K, Matthews KR. 2009. A surface transporter family conveys the trypanosome differentiation signal. Biochemistry 459:213-217. doi:10.1038/nature07997.A

Dejung M, Subota I, Bucerius F, Dindar G, Freiwald A, Engstler M, Boshart M, Butter F, Janzen CJ. 2016. Quantitative Proteomics Uncovers Novel Factors Involved in Developmental Differentiation of Trypanosoma brucei. PLoS Pathog 12:1-20. doi:10.1371/journal.ppat.1005439

Engstler M, Boshart M. 2004. Cold shock and regulation of surface protein trafficking convey sensitization to inducers of stage differentiation in Trypanosoma brucei. Genes Dev 18:2798-2811. doi:10.1101/gad.323404

Flynn RA, Chang HY. 2014. Long noncoding RNAs in cell-fate programming and reprogramming. Cell Stem Cell 14:752-761. doi:10.1016/j.stem.2014.05.014

Geisler S, Coller J. 2013. RNA in unexpected places: long non-coding RNA functions in diverse cellular contexts. Nat Rev Mol Cell Biol 14:699-712. doi:10.1038/nrm3679

Guizetti J, Barcons-Simon A, Scherf A. 2016. Trans-acting GC-rich non-coding RNA at var expression site modulates gene counting in malaria parasite. Nucleic Acids Res 44:97109718. doi:10.1093/nar/gkw664

Kang YJ, Yang DC, Kong L, Hou M, Meng YQ, Wei L, Gao G. 2017. CPC2: A fast and accurate coding potential calculator based on sequence intrinsic features. Nucleic Acids Res 45:W12-W16. doi:10.1093/nar/gkx428

Kelly S, Reed J, Kramer S, Ellis L, Webb H, Sunter J, Salje J, Marinsek N, Gull K, Wickstead B, Carrington M. 2007. Functional genomics in Trypanosoma brucei: A collection of vectors for the expression of tagged proteins from endogenous and ectopic gene loci. Mol Biochem Parasitol 154:103-109. doi:10.1016/j.molbiopara.2007.03.012

Kielbasa SM, Wan R, Sato K, Frith MC, Horton P. 2011. Adaptive seeds tame genomic sequence comparison. Genome Res 21:487-493. doi:10.1101/gr.113985.110

Kolev NG, Franklin JB, Carmi S, Shi H, Michaeli S, Tschudi C. 2010. The transcriptome of the human pathogen Trypanosoma brucei at single-nucleotide resolution. PLoS Pathog 6:1-15. doi:10.1371/journal.ppat.1001090

Kretz M, Siprashvili Z, Chu C, Webster DE, Zehnder A, Qu K, Lee CS, Flockhart RJ, Groff AF, Chow J, Johnston D, Kim GE, Spitale RC, Flynn RA, Zheng GXY, Aiyer S, Raj A, Rinn JL, Chang HY, Khavari PA. 2013. Control of somatic tissue differentiation by the long non-coding RNA TINCR. Nature 493:231-235. doi:10.1038/nature11661 
Kretz M, Webster DE, Flockhart RJ, Lee CS, Zehnder A, Lopez-Pajares V, Qu K, Zheng GXY, Chow J, Kim GE, Rinn JL, Chang HY, Siprashvili Z, Khavari PA. 2012. Suppression of progenitor differentiation requires the long noncoding RNA ANCR. Genes Dev 26:338-343. doi:10.1101/gad.182121.111

McDonald L, Cayla M, Ivens A, Mony B, MacGregor P, Silvester E, McWilliam K, Matthews KR. 2018. Non-linear hierarchy of the quorum sensing signalling pathway in bloodstream form African trypanosomes, PLOS Pathogens. doi:10.1371/journal.ppat.1007145

Menard KL, Haskins BE, Colombo AP, Denkers EY. 2018. Toxoplasma gondii Manipulates Expression of Host Long Noncoding RNA during Intracellular Infection. Sci Rep 8:114. doi:10.1038/s41598-018-33274-5

Mony BM, MacGregor P, Ivens A, Rojas F, Cowton A, Young J, Horn D, Matthews K. 2014. Genome-wide dissection of the quorum sensing signalling pathway in Trypanosoma brucei. Nature 505:681-685. doi:10.1038/nature12864

Mony BM, Matthews KR. 2015. Assembling the components of the quorum sensing pathway in African trypanosomes. Mol Microbiol 96:220-232. doi:10.1111/mmi.12949

Ransohoff JD, Wei Y, Khavari PA. 2018. The functions and unique features of long intergenic non-coding RNA. Nat Rev Mol Cell Biol 19:143-157. doi:10.1038/nrm.2017.104

Rijo-Ferreira F, Pinto-Neves D, Barbosa-Morais NL, Takahashi JS, Figueiredo LM. 2017. Trypanosoma brucei metabolism is under circadian control. Nat Microbiol 2. doi:10.1038/nmicrobiol.2017.32

Rinn JL, Chang HY. 2012. Genome Regulation by Long Noncoding RNAs. Annu Rev Biochem 81:145-166. doi:10.1146/annurev-biochem-051410-092902

Savić N, Bär D, Leone S, Frommel SC, Weber FA, Vollenweider E, Ferrari E, Ziegler U, Kaech A, Shakhova O, Cinelli P, Santoro R. 2014. LncRNA maturation to initiate heterochromatin formation in the nucleolus is required for exit from pluripotency in ESCs. Cell Stem Cell 15:720-734. doi:10.1016/j.stem.2014.10.005

Silvester E, McWilliam K, Matthews K. 2017. The Cytological Events and Molecular Control of Life Cycle Development of Trypanosoma brucei in the Mammalian Bloodstream. Pathogens 6:29. doi:10.3390/pathogens6030029

Trindade S, Rijo-Ferreira F, Carvalho T, Pinto-Neves D, Guegan F, Aresta-Branco F, Bento F, Young SA, Pinto A, Van Den Abbeele J, Ribeiro RM, Dias S, Smith TK, Figueiredo LM. 2016. Trypanosoma brucei Parasites Occupy and Functionally Adapt to the Adipose Tissue in Mice. Cell Host Microbe 19:837-848. doi:10.1016/j.chom.2016.05.002

Vasquez JJ, Hon CC, Vanselow JT, Schlosser A, Siegel TN. 2014. Comparative ribosome profiling reveals extensive translational complexity in different Trypanosoma brucei life cycle stages. Nucleic Acids Res 42:3623-3637. doi:10.1093/nar/gkt1386

Vassella E, Reuner B, Yutzy B, Boshart M. 1997. Differentiation of African trypanosomes is controlled by a density sensing mechanism which signals cell cycle arrest via the cAMP pathway. J Cell Sci 110:2661-2671.

Yang X, Figueiredo LM, Espinal A, Okubo E, Li B. 2009. RAP1 Is Essential for Silencing Telomeric Variant Surface Glycoprotein Genes in Trypanosoma brucei. Cell 137:99109. doi:10.1016/j.cell.2009.01.037

Yao RW, Wang Y, Chen LL. 2019. Cellular functions of long noncoding RNAs. Nat Cell Biol 21:542-551. doi:10.1038/s41556-019-0311-8

Zhang LF, Huynh KD, Lee JT. 2007. Perinucleolar Targeting of the Inactive X during S Phase: Evidence for a Role in the Maintenance of Silencing. Cell 129:693-706. doi:10.1016/j.cell.2007.03.036 
bioRxiv preprint doi: https://doi.org/10.1101/2020.05.03.074625; this version posted May 3, 2020. The copyright holder for this preprint

(which was not certified by peer review) is the author/funder, who has granted bioRxiv a license to display the preprint in perpetuity. It is made available under aCC-BY-NC-ND 4.0 International license.

613 Additional Files

614

615 Table supplement $1-5$

616 Figure supplement $1-9$

617 References (22 - 33)

618

\section{$619 \quad$ Figures}

620

621 
Figure 1. Identification of 1,428 IncRNAs in T. brucei.

624 (A) Pipeline used for the identification of lncRNAs genes in T. brucei. (1) Strand-specific and 625 paired-end RNA-seq. (2) Ksplice identified putative genes whose transcripts contained a 626 spliced-leader sequence (SL) and a poly(A) tail (PA) at the extremities. Ksplice used LAST 627 (Kielbasa et al., 2011) to map RNA-seq reads to T. brucei genome. (3) The non-coding nature 628 of the putative lncRNAs was predicted from a low CPC score, poor association with ribosomes, 629 and no detectable peptides. Grumpy lncRNA is intergenic and immediately upstream of RBP7 630 genes, previously shown to be involved in SIF-dependent pathway. (B) Subcellular localization 631 of Ksplice long noncoding RNA genes in slender, stumpy, and procyclic forms of T. brucei, 632 using RNA-FISH. (C) Number of Ksplice lncRNA genes that causes loss of parasite fitness upon downregulation by RNA interference (extracted from RIT-seq analysis (Alsford et al., 2011)). RNA interference was induced in bloodstream forms for 3 days (BSD3) - 278 lncRNAs; in bloodstream forms for 6 days (BSD6) - 341 lncRNAs; during in vitro parasite differentiation from bloodstream to insect procyclic forms (DIF) - $400 \mathrm{lncRNAs}$; in procyclic 637 forms, PF - 402 lncRNAs. The total number of lncRNA genes essential for parasite fitness in 638 this screen was 649. 


\section{A. Ksplice algorithm - IncRNA}

1 Strand-specific paired-end RNA-sequencing

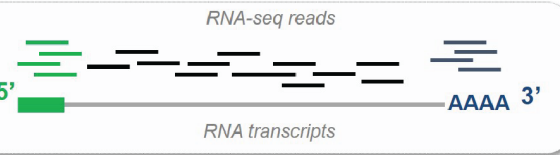

1. Extract reads containing $S L$ or $P A$
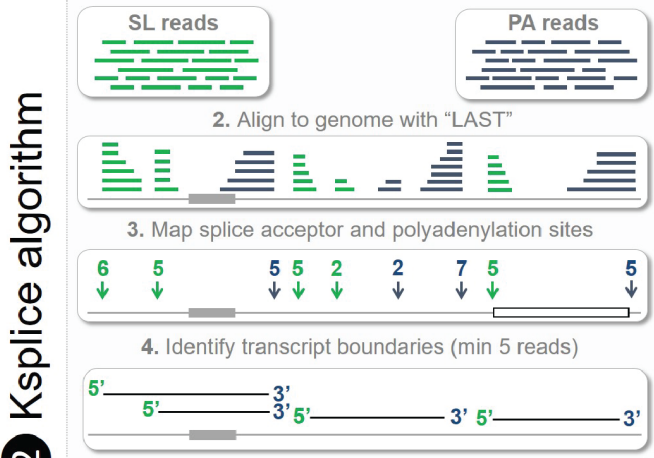

6745 annotated genes 1931 novel genes 72 Kolev ncRNAs

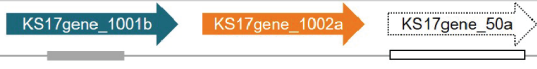

CPC2 1883 novel genes 72 Kolev ncRNAs

0
क
$\frac{0}{0}$
$\frac{1}{0}$
$\frac{0}{0}$
$\frac{1}{2}$
$\frac{0}{2}$
$\frac{1}{2}$

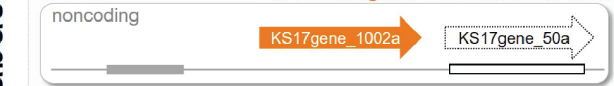

Ribosome profiling 1761 novel genes 64 Kolev ncRNAs no or few interactions

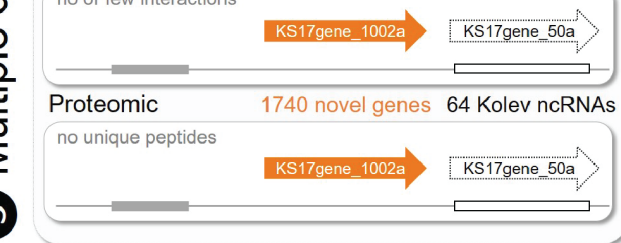

Chr.10 1428 new IncRNAs

Tb927.10.12080 GRUMPY RBP7A RBP7B

SIF pathway
B. RNA-FISH - IncRNA

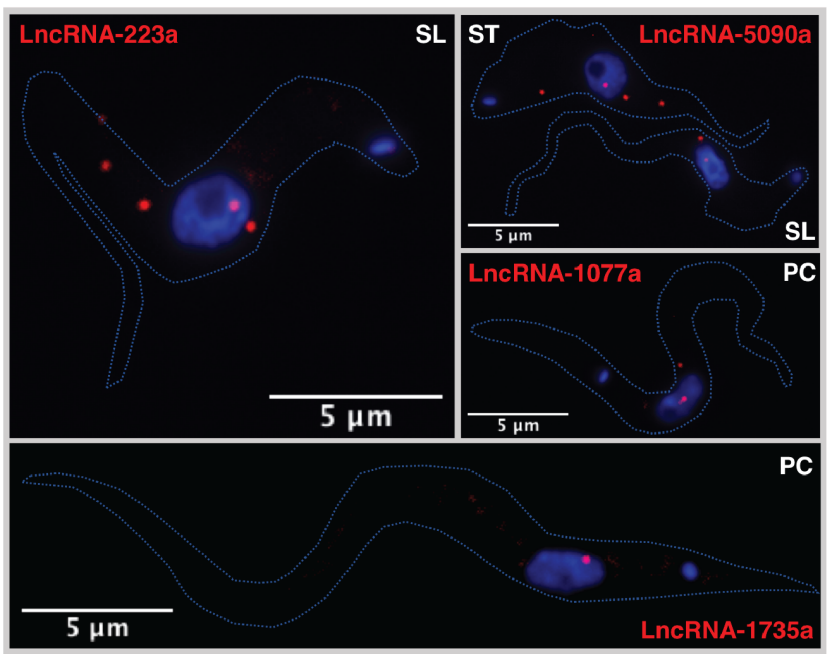

C. Loss-of-function - IncRNA

BSD6

DIF

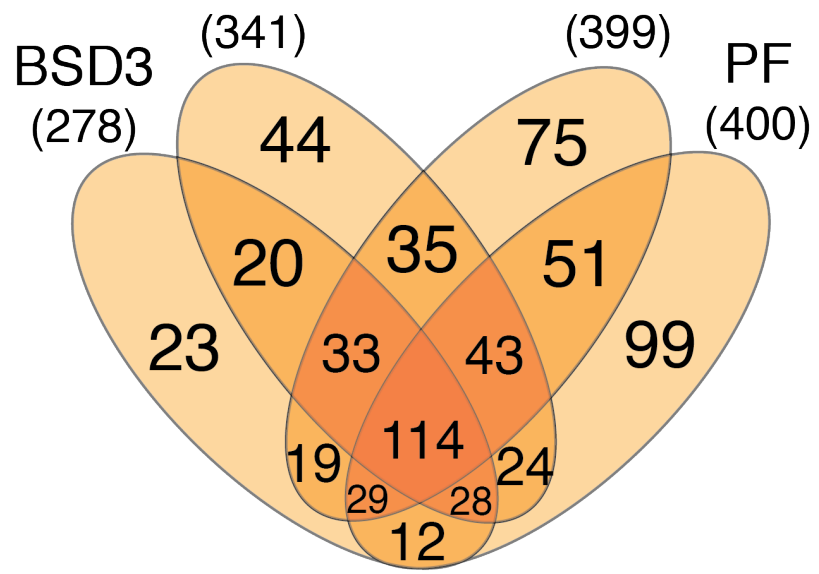

Total (649) 
641 Figure 2. Dynamic subnuclear localization of grumpy during parasite differentiation.

642 (A) Ribosome association of grumpy and its neighboring genes was assessed by analyzing 643 previously published ribosome profiling datasets: Mapping of RNA-seq reads from 644 bloodstream forms (BSF-RNA) or procyclic forms (PF-RNA); mapping of ribosome profiling 645 reads from bloodstream forms (BSF-RT) or procyclic forms (PF-RT). (B) Sequencing and 646 accurate mapping of the 5' and 3' ends of the grumpy lncRNA using circular RT-PCR (cRT647 PCR). Black outlined arrows show the position of splice acceptor site (SL) and polyadenylation 648 sites (PA) identified with our Ksplice algorithm in the grumpy gene locus. Orange outlined 649 arrows show the grumpy transcript isoforms that we sequenced using cRT-PCR and the number 650 of clones sequenced for each isoform. (C) Transcript level changes during the transition from 651 slender to stumpy forms, measured by qRT-PCR. Stumpy formation was induced by pCPT652 cAMP (C3912 Sigma-Aldrich). Diff (Tb927.10.12970) is used as control to normalize transcript levels (Barquilla et al., 2008). PAD1 and GFP genes are used as controls to estimate parasite differentiation into stumpy forms. 10.10280 (Tb927.10.12080) is the gene upstream of grumpy. Results are shown as mean (SEM, $n=3$ ). Dunnett's multiple comparisons test is used for statistical analysis using the time point $\mathrm{Oh}$ as the control for comparison (Adjusted $\mathrm{P}$ value: $*<0,05 ; * *<0,01 ; * * *<0,001$ ). (D) Subcellular localization of grumpy during the transition from slender to stumpy forms using RNA-FISH. Time points $(0 \mathrm{~h}, 12 \mathrm{~h}, 24 \mathrm{~h}, 36 \mathrm{~h}, 48)$ of parasite differentiation after addition of the pCPT-cAMP stimulus to the culture medium. DIC: Differential interference contrast microscopy image of $T$. brucei; GFP: GFP::PAD1 signal expressed in nucleus of stumpy forms; GRUMPY: grumpy signal using RNA-FISH (Stellaris 662 probes). 


\section{A. Ribosome profiling - Grumpy}

Tb927_10_v5.1

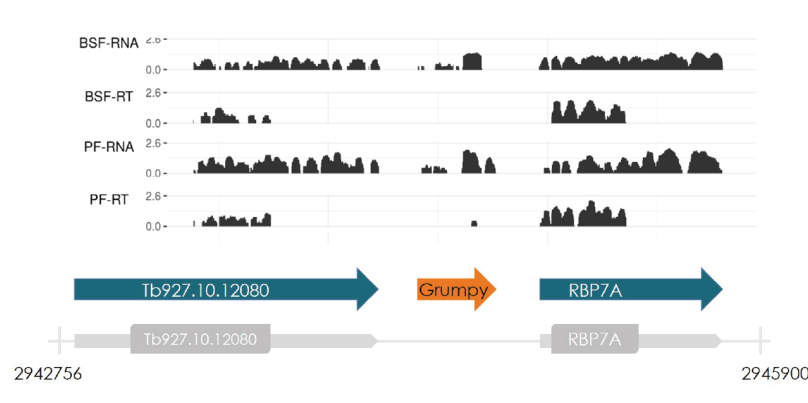

\section{Quantitative PCR - Grumpy}

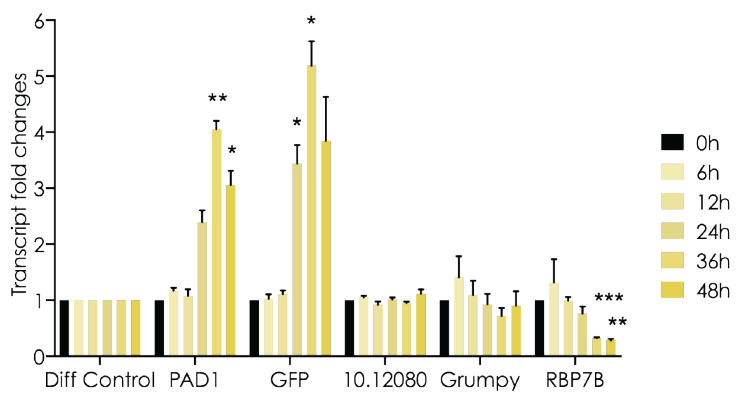

D. RNA-FISH - Grumpy

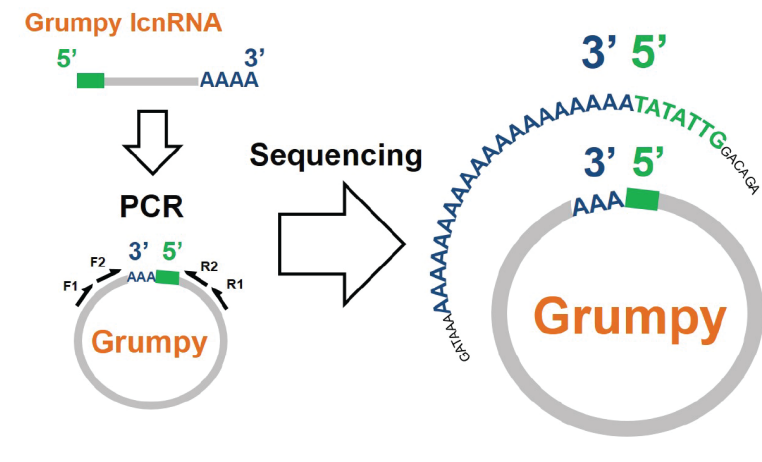

Splice-acceptor and poly(A) sites - Grumpy
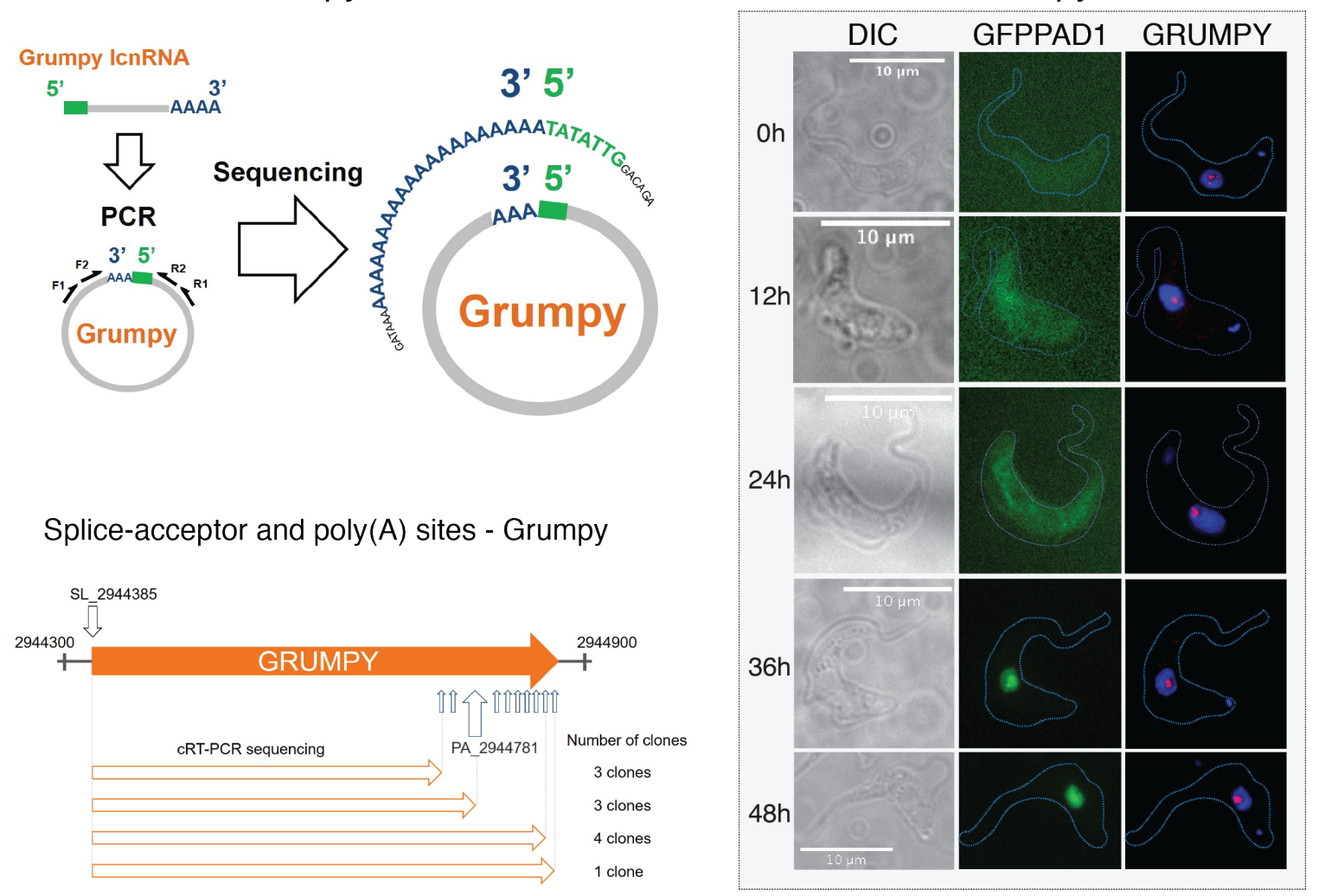
666 Figure 3. Grumpy over-expression promotes premature parasite differentiation.

667 (A) Subcellular localization of grumpy after over-expression using RNA-FISH. Left-to-right:

668 GRUMPY: grumpy signal using RNA-FISH; Phase contrast signal of T. brucei parasite ; GFP:

669 GFP::PAD1 signal expressed in the nucleus of stumpy forms. (B) Transcript levels measured

670 by qRT-PCR of grumpy and its neighbouring genes in parental cell line (black bars) and in

671 grumpy over-expressing cell line (yellow bars). Changes of transcript levels were measured by

672 normalizing transcript level to a control gene (Tb927.10.12970) and to the parental cell line.

673 (C) Growth in parasites over-expressing grumpy (without passage) for 6 days. (D) Percentage

674 of live cells measured by FACS of propidium iodide-stained cells after inducing grumpy

675 overexpression. (E) Percentage of GFP::PAD1 positive parasites (stumpy forms) measured by

676 FACS after inducing grumpy over-expression. (F) Percentage of parasites expressing both

677 GFP::PAD1 and endogenous PAD1 protein are measured by microscopy and image

678 quantification, after inducing grumpy over-expression. Microscopy picture (on the left) showed

679 an example of parasite expressing both GFP::PAD1 in the nucleus (in green) and the

680 endogenous PAD1 protein at the cell surface (in red). Parasite DNA stained with DAPI (in

681 blue). (G) Cell cycle profile of parental cell line (slender forms) and grumpy-over-expressing

682 parasites at day 3 and 4 of in vitro culture without passage. (H) Differentiation assay to

683 separately follow the transition from slender to stumpy and stumpy to procyclic forms.

684 Parasites were cultured for 2 days without passage, in the presence or absence of tetracyclin.

685 GFP::PAD1 expression was measured by FACS to score the percentage of stumpy forms.

686 Parasites were transferred to DTM medium containing cis-acconitate and placed for $12 \mathrm{~h}$ at

$68727^{\circ} \mathrm{C}$. The percentage of procyclic forms was quantified by flow cytometry using procyclin

688 antibody. Results from Panel $B$ to $H$ are shown as mean (SEM, $n=3$ ). Sidak's multiple

689 comparisons test is used for statistical analysis using the parental cell line as the control for

690

691 comparison (Adjusted P value: $*<0,05 ; * *<0,01 ; * * *<0,001, * * * *<0,0001$ ). 
bioRxiv preprint doi: https://doi.org/10.1101/2020.05.03.074625; this version posted May 3, 2020. The copyright holder for this preprint (which was not certified by peer review) is the author/funder, who has granted bioRxiv a license to display the preprint in perpetuity. It is made available under aCC-BY-NC-ND 4.0 International license.

A. RNA-FISH - Grumpy-OE

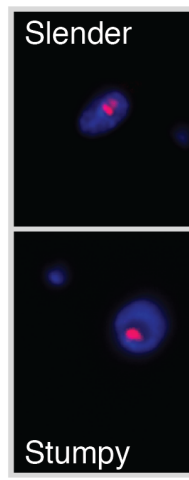

C. Growth curve in vitro

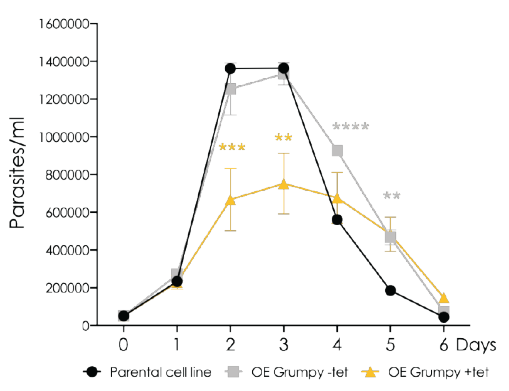

F. PAD1 protein expression
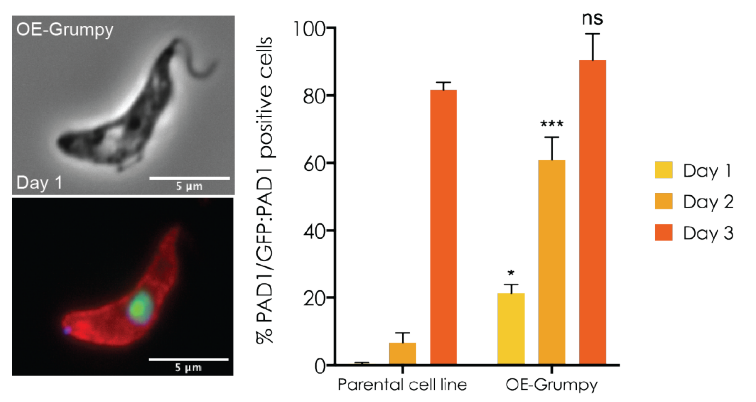

H. Functional stumpy forms

D. Live cells in vitro

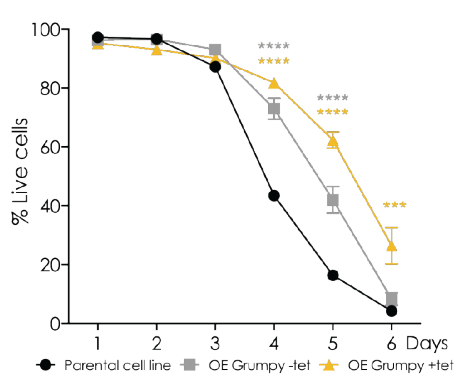

B. Grumpy-OE

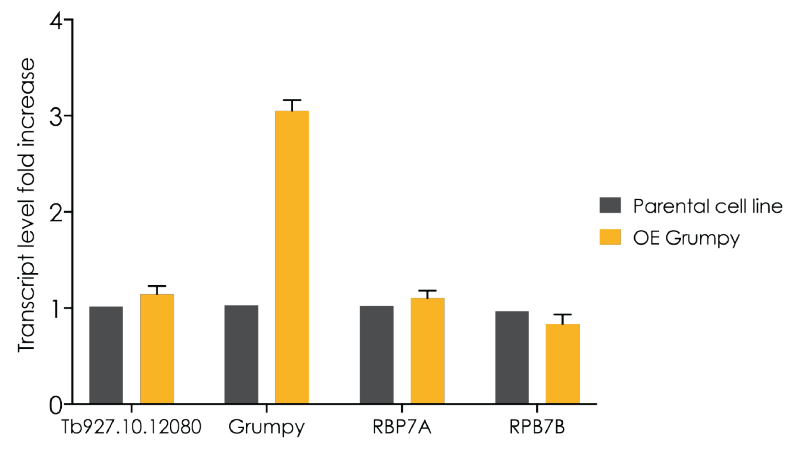

E. Stumpy forms in vitro

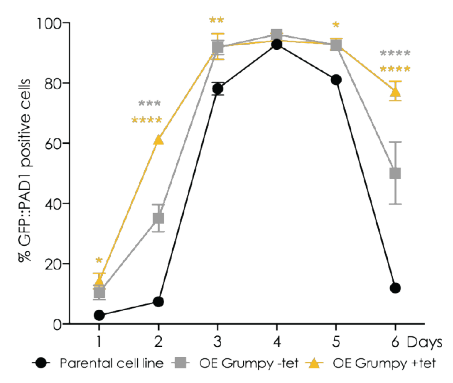

G. Cell cycle profile
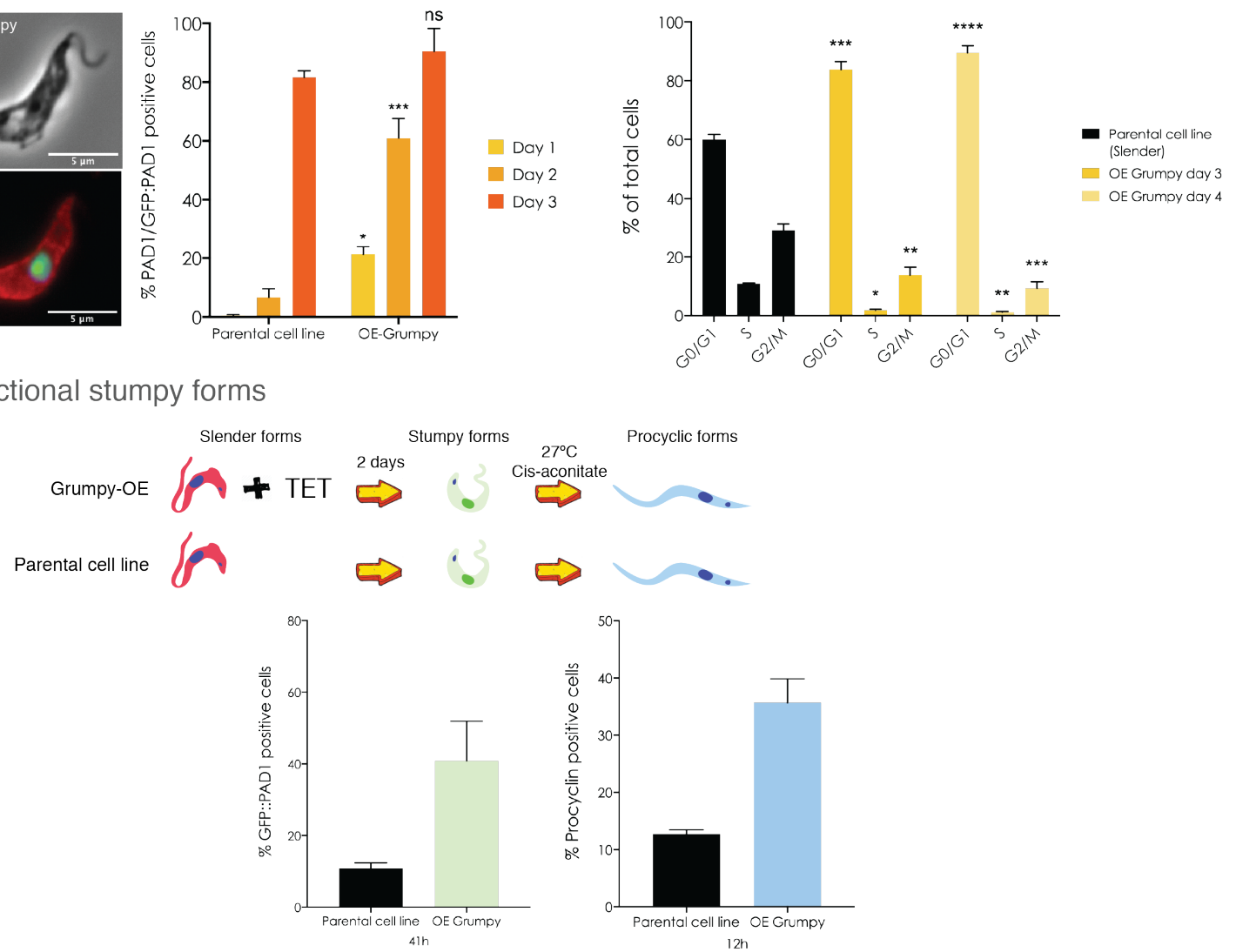
694 Figure 4. Over-expression of grumpy promotes premature differentiation into stumpy 695 forms in vivo and prolongs mouse survival.

696 (A) Parasitemia in mice infected with the parental cell line (black line) or with a grumpy-over697 expressing cell line. Grumpy over-expression was either not induced or induced by adding 698 doxycycline to drinking water either at Day 0 (purple curve) or Day 4 (yellow curve) of 699 infection. Results are shown as the mean (SEM, $n=4)$. Dunnett's multiple comparisons test is 700 used for statistical analysis using the parental cell line as the control (Adjusted P value: ** $701<0,01 ; * * *<0,001$ ). (B) Mice survival rates according to the type of infection described in 702 panel A. Log rank (Mantel-Cox) test for comparisons of Kaplan-Meier survival curves 703 indicates a significant increase in the survival rates in mice infected with grumpy-over704 expressing cell-line parasites compared to mice infected with the parental cell line. $\varphi \varphi$, $705 p=0.0067$. $\varphi, p=0.0177$. (C) Fraction of mice with at least $20 \%$ of GFP::PAD1 positive 706 parasites (=stumpy forms) in the blood as a function of the parasitemia. Log rank (Mantel-Cox) 707 test for comparisons of Kaplan-Meier curves indicates a significant premature parasite 708 differentiation into stumpy forms in mice infected with grumpy-overexpressing cell line 709 parasites compared to mice infected with the parental cell line. $\varphi \varphi, p=0.0067 . \varphi, p=0.0177$. 


\section{A. Parasitemia}

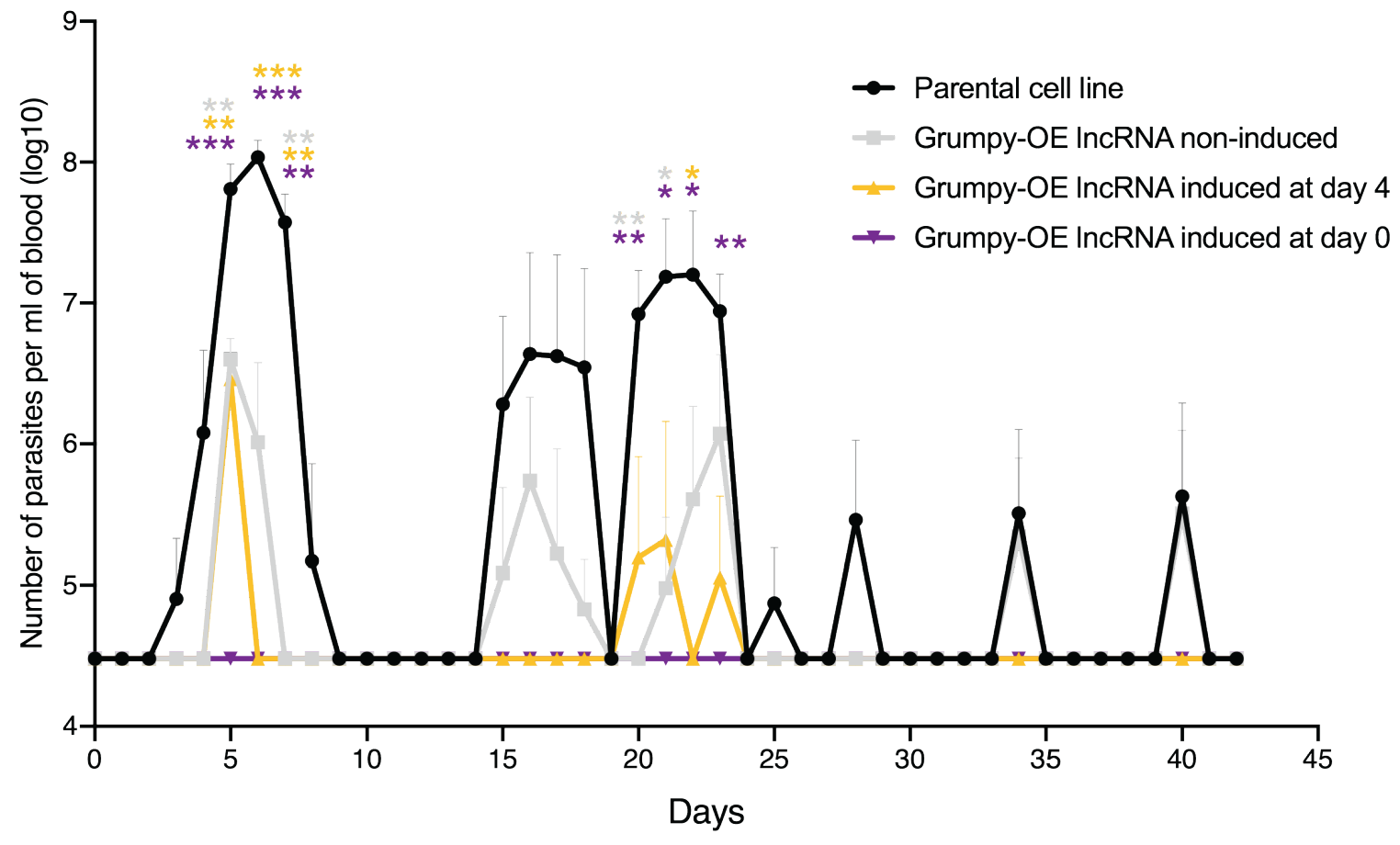

B. Mouse survival

C. Stumpy formation
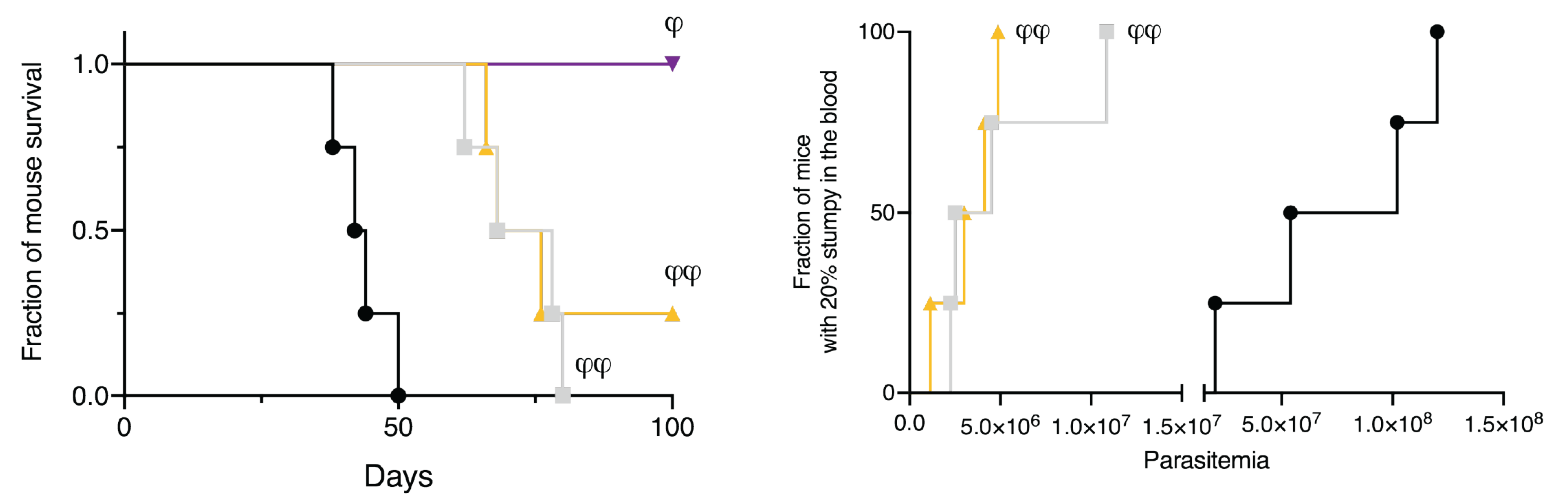